\title{
Evaluation of the Shear Strength of Orthodontic Bands Cemented with New Composite Using Adhesive System
}

\author{
Evaluación de la Resistencia al Cizallamiento de Bandas Ortodónticas \\ Cementadas con Nuevo Compuesto Utilizando Sistema Adhesivo
}

\author{
Kalena Melo Maranhão1; Fernanda Neves²; Ana Cassia Reis³; Pablo Maranhão4; \\ Joyce Gatti ${ }^{5}$; Gustavo Brandão; Eliza Klautau $^{6}$ \& Dario Azevedo 5
}

\begin{abstract}
MARANHÃO, K. M.; NEVES, F.; REIS, A. C.; MARANHÃO, P.; GATTI, J.; BRANDÃO, G.; KLAUTAU, E. \& AZEVEDO, D. Evaluation of the shear strength of orthodontic bands cemented with new composite using adhesive system. Int. J. Odontostomat., 12(4):407-411, 2018.
\end{abstract}

\begin{abstract}
Orthodontic cements have been used to enhance retention between the band and the crown, however, unfavorable properties found in many of these cements may contribute to cement failure between band and crown's surface and leading to unsuccessful application of orthodontic forces. The aim of this study was to evaluate the shear strength of the Orthobite composite (FGM) using the Single Bond adhesive system (3M). The sample consisted of 30 bovine incisors divided in 2 groups $(n=15)$. All teeth were submitted to prophylaxes with pumice stone and etching with phosphoric acid. In Group I the Orthobite was used conventionally. Group II was similar to Group I, however, the Single Bond adhesive system was applied after conditioning. The samples were stored in distilled water in incubator at $37^{\circ} \mathrm{C}$ for $24 \mathrm{~h}$ and submitted to the shear strength test at a speed of $0.5 \mathrm{~mm} /$ minute speed. Data were submitted to the Student T test ( $5 \%$ ). The results (MPa) showed no statistically significant differences between the groups, regardless of surface treatment. Thus, all groups exhibited adequate adhesive bond strength for clinical use.
\end{abstract}

KEY WORDS: shear strength, orthodontics, dentistry.

\section{INTRODUCTION}

Recently, orthodontics has evolved considerably, even though the diagnosis and treatment plan were considered prime factors in the success of the therapy, with the technological advancement as well as development and improvement of new materials, it has resulted in a greater effectiveness in the dental movement, resulting in an improved quality of treatment.

The cementation of bands in the posterior teeth is a common procedure in orthodontic practice, especially in many situations where the orthodontic rings are still indispensable as in the use of extra-oral appliances, auxiliary devices and teeth with very short clinical crowns (Millett et al., 2003; Caglaroglu et al., 2014; Linjawi \& Abbassy, 2016).

The cements are used to fill the discrepancies of adaptation between the band and the dental remnant, favoring the frictional retention between both, resulting in a procedure with good margins and resistance to removal and / or displacement (Linjawi \& Abbassy; Millett et al., 2003). Thus, a stable union between the tooth and the band is critical for the correct application of forces and, consequently, for the success of orthodontic treatment (Millett et al., 2001; Williams et al., 2005; Godoy-Bezerra et al., 2006; Caglaroglu et al.).

\footnotetext{
${ }^{1}$ Professor, UNINASSAU'S Dental School, Belém, Pará, Brazil.

2 Undergraduate student, ESAMAZ'S Dental School, Belém, Pará, Brazil.

${ }^{3}$ Professor, FAMAZ'S Dental School, Belém, Pará, Brazil.

${ }^{4}$ Student, UEPA'S Medical School, Belém, Pará, Brazil.

${ }^{5} \mathrm{PhD}$, Professor, ESAMAZ'S Dental School, Belém, Pará, Brazil.

${ }^{6}$ PhD, Professor, UFPA'S Dental School, Belém, Pará, Brasil.
} 
As to the materials currently available for cementing orthodontic bands, there are several systems manufactured specifically for this purpose on the market (Jobalia et al., 1997; Chung et al., 1999; Choo et al., 2001; Movahhed et al., 2005; Lee \& Kanavakis 2016). Although glass ionomer cements are proven to be efficient and long-term in orthodontics, not all practitioners adapt and opt for their use, which may be due to the consistency of the material, the presentation and the high cost of being an imported material (Wilson \& Kent, 1972; Cheng et al., 2001; Maranhão \& Klautau, 2008; Gaviria et al., 2013; Kalcıog lu et al., 2015).

Among the current composites that are emerging in the market, orthobite, a low cost photopolymerizable national material, has recently been used by orthodontists, whose study has been little explored. The use of photopolymerizable resins has been greatly expanded due to some advantages such as better and more precise work, with decreasing of an increasingly scarce variable, time.

As for its use, orthobite has been commonly employed without the prior application of adhesive. Thus, the present study aimed to evaluate the performance of this material as it has been commonly used in the orthodontic clinic and with the use of an adhesive system, regarding the shear strength and IRA requirements on the dental surface after the orthodontic bands.

\section{MATERIAL AND METHOD}

Thirty dental elements of animal (bovine) origin were used. These elements were chosen because similar to the human tooth, obeying the following criteria: good state of conservation, unirradicular hygiene, and crowns and roots similar in size and volume. After being cleaned in tap water, they were decontaminated in 0.5 $\%$ thymol solution at room temperature, then stored in distilled water for seven days.

Initially, the specimens were standardized, delimiting $4.0 \mathrm{~mm}$ below the cervical line (graft margin) using a graphite pencil (HB 2.0), taking the vestibular surface as a reference. The roots were then cut with a flexible diamond disk (KG Sorensen Brazil) coupled to the low-speed turbine.

Rings of PVC $(20 \times 20 \mathrm{~mm})$ were prepared, which were then filled with liquid acrylic resin. Later, all the crowns were incorporated in the resin in the central region of each ring, leaving only the vestibular faces of the crowns exposed. The objective was to ensure that the buccal face of each tooth was horizontally to the flat surface of the base in the resin. Thereafter, the PVC rings were removed after complete polymerization of the resin and the samples stored in distilled water.

For the cementation 30 band strips segments were used measuring $10 \times 4,8 \mathrm{~mm}$ (Morelli, Sorocaba, $\mathrm{SP}$ ) on which 30 molar brackets (Morelli, Sorocaba, $\mathrm{SP})$ were welded, all with four welding points.

Band division and band cementation procedures: Group I - 15 bands were cemented with orthobite (FGM, Joinville, Brasil), according to the recommendations of the manufacturer and Group II 15 bands were cemented with orthobite (FGM, Joinville, Brasil), where Single Bond (3M, Minnesota, EUA) adhesive was used.

Once the groups were divided, the cementation procedure was started. First, a profilax was performed on the buccal surface of the pumice samples for 10 seconds. Soon after, the teeth were washed with air / water spray for 30 seconds and dried with oil-free compressed air for the same time.

The crowns were totally air dried and distributed randomly and equally in each experimental group, dividing them into two groups. The band receiving area was conditioned with a $37 \%$ phosphoric acid gel (Alpha Acid, DFL, Brasil) for 30 seconds, applied with a syringe. The teeth were washed for 30 seconds and dried for 20 seconds until a whitish appearance. Then, with a micro brush, a thin layer of the adhesive was applied in the group where this procedure was necessary, covering the conditioned area.

All cementation procedures followed the manufacturer's recommendations with standardized pressure. The resin was dispensed on the basis of each band in a homogeneous way and this was positioned and pressed on the surface of the tooth by means of a forceps holder until the maximum flow is obtained. Excesses were removed by means of an exploratory probe, on all sides of the bracket.

A Radll high power LED light unit (SDI, Victoria, Australia) was used in the photo activation of the fixation systems, being positioned perpendicular to each proximal face of the bracket, for 20 seconds each. Subsequently, the specimens were stored for 24 hours 
at room temperature in the absence of light in plastic containers containing distilled water prior to the performance of the adhesive strength test. The shear test was performed after 24 hours.

The shear strength test the universal testing machine (Emic, linha DL, São José dos Pinhais, Brasil) was also used, using a matrix with a loading chisel with $2 \mathrm{~mm}$ thickness in contact with the bracket, with a crosshead speed of $0,5 \mathrm{~mm} / \mathrm{min}$. The maximum strength was recorded in Newtons $(\mathrm{N})$ at the time of rupture and converted into Mpa.

After debonding, specimens were visually assessed to determine the site of cement failure and were classified by the adhesive remnant index (ARI) as originally proposed by Artun \& Bergland (1984). Scoring was as follows: 0 , no cement remains on the tooth surface; 1 , less than half of the tooth surface is covered by cement; 2 , more than half of the tooth surface is covered by cement; and 3, all of the tooth surface under the band is covered by cement.

Statistical Analysis. $95 \%$ confidence intervals were constructed for the population means of the experimental groups. These intervals allow researchers to quantify the differences between the means since the tests only indicate whether or not there is evidence that these differences are significant at $5 \%$. The SBS values were compared using test t-student for intergroup comparisons. The Kruskal-Wallis nonparametric test was used-at $5 \%$ significance level-to evaluate the adhesive remnant index.

\section{RESULTS}

When comparing shear strength values (Table I), no statistically significant differences were found between groups $(p>0.05)$. Orthobite specimens failed predominantly at the cement/band interface.

Table I: Mean shear bond strength data for each cement used in the study

\begin{tabular}{lcc}
\hline & OrthoBite & Orthobite \\
\hline $\mathrm{N}=$ & 15 & 15 \\
Average $=$ & 1.9857 & 2.5107 \\
Variânce $=$ & 0.1199 & 0.1256 \\
$\mathrm{t}=$ & 3.9643 & --- \\
$\mathrm{p}=$ & 0.0005 & --- \\
standard deviation $=$ & 0.525 & --- \\
$\mathrm{IC} 95 \%=$ & $0.2527 \mathrm{a}$ & \\
\hline
\end{tabular}

In the evaluation of the Adhesive Remnant Index (IRA), scores were observed within each group, as shown in Table II.

Table II. Adhesion remainder index scores (ARI) presented by the groups.

\begin{tabular}{|c|c|c|c|c|}
\hline GROUP & \multicolumn{4}{|c|}{ Scores (ARI) } \\
\hline & 0 & 1 & 2 & 3 \\
\hline 1 & 0 & & 2 & 13 \\
\hline 2 & 0 & & 1 & 14 \\
\hline
\end{tabular}

$0=$ no quantity of adhesive adapted to enamel

$1=$ less than the half of the sticker adhesive

$2=$ more than the half of the adhesive to the enamel

$3=$ all bumper sticker

\section{DISCUSSION}

Among the new orthodontic materials, Orthobite was developed specifically for Orthodontics, which according to the manufacturer, in addition to presenting in two color compositions (blue and pink) which would facilitate the removal of this material after takeoff, this product can be used on surfaces dry, damp or contaminated, without compromising the fixation. The use of this compound alone with the acid, reduces the steps of the cementation technique and minimizes possible errors in the enamel conditioning.

As can be observed, with respect to the results of shear strength of the two groups studied, no statistical differences between the different surface treatments were found. Since the basic composition of the specific resins for Orthodontics resembles that found in restorative resins, it was believed in this study that these could present real conditions to be used in Orthodontics, satisfying the minimum acceptable values acceptable the shear strength of orthodontic devices, which according to Reynolds (1975), should be between 4.9 MPa and 7.8 MPa (Nakamichi et al., 1983; Herion et al., 2007; Millett et al., 2009; Santos et al., 2010; Nalawade et al., 2013; Sharma et al., 2014; Caglaroglu et al.).

When an in vitro study is carried out, it is noted that there are limitations imposed by the technique and sometimes it is difficult to compare the results obtained due to the lack of standardization of the techniques and materials used by the researcher during the accomplishment of a research work (Millett et al. 2003; Godoy-Bezerra et al.; Millett et al. 2009; Caglaroglu et al.; Linjawi \& Abbassy). 
By microscopic analysis, the enamel surface where the band was cemented was observed according to the scale proposed by Artun \& Bergland. The authors' aim is to quantify the remaining material on the enamel, showing the place where the fracture occurred during the shear test. There was no difference in the type of take-off in adhesive and non-adhesive materials. In all groups there was a predominance of the score 3 , which according to Artun \& Bergland all the material was adhered to the enamel after the take-off, that is, the majority of the fractures occurred a large incidence of adhesive failure in the band / material interface. This type of fracture is a result of the micromechanical union created between the composite and the tooth, causing adhesive failure between the band and the material. These results are found in works in the literature (Choo et al.; Movahhed et al.; Herion et al.; Millett et al. 2009; Caglaroglu et al.; Lee \& Kanavakis).

In addition to the observation of the occurrence of adhesive fractures, the use of resins with high content of charge particles should be considered. The use of such resins is not always recommended, especially in dental elements that have fracture lines on their surfaces that have been bleached or lost their vitality for a long time due to the greater risk of surface fracture.

\section{CONCLUSION}

After analysis of the results, all groups tested showed adequate shear strength to meet the clinical needs. Regarding IRA, there was no difference between the groups, and most of the fractures occurred at the band / material interface. It is extremely important that the orthodontist have knowledge of the properties of the material used, not only the advantages but also the limitations. It is necessary to follow manufacturer's recommendations so that the quality of the chosen material can be maximized. Thus, the mere fact that one cement is mechanically stronger than the other does not confer a guarantee of clinical success.

MARANHÃO, K. M.; NEVES, F.; REIS, A. C.; MARANHÃO, P.; GATTI, J.; BRANDÃO, G.; KLAUTAU, E. \& AZEVEDO, D. Evaluación de la resistencia al cizallamiento de bandas ortodónticas cementadas con nuevo compuesto utilizando sistema adhesivo. Int. J. Odontostomat., 12(4):407-411, 2018.

RESUMEN: Los cementos ortodónticos se han utilizado para aumentar la retención entre la banda y la corona, sin embargo, las propiedades desfavorables encontradas en muchos de estos ce- mentos pueden contribuir a la falla del cemento entre la superficie de la banda y la corona y llevar a la aplicación incorrecta de fuerzas de ortodoncia. El objetivo de este trabajo fue evaluar la resistencia al cizallamiento del compuesto Orthobite (FGM) utilizando el sistema adhesivo Single Bond (3M). La muestra consistió de 30 incisivos bovinos divididos en dos grupos $(n=15)$. Todos los dientes recibieron profilaxis con piedra pómez y acondicionamiento del esmalte con ácido fosfórico. En el Grupo I, se utilizó Orthobite de manera convencional. El Grupo II fue similar al I, pero se aplicó el sistema adhesivo Single Bond, después de acondicionamiento. Los cuerpos de prueba fueron almacenados en agua destilada en estufa a $37^{\circ} \mathrm{C}$ por $24 \mathrm{~h}$ y sometidos al ensayo de resistencia al cizallamiento, con velocidad de $0,5 \mathrm{~mm}$ por minuto. Los datos fueron sometidos a la prueba de T Student (5\%). Los resultados (en $\mathrm{MPa}$ ) no mostraron diferencias estadísticamente significativas entre los grupos, independientemente del tratamiento de la superficie. De esta forma, todos los grupos presentaron resistencia adhesiva adecuada para uso clínico.

PALABRAS CLAVE: resistencia al cizallamiento, ortodoncia, odontología.

\section{REFERENCES}

Artun, J. \& Bergland, S. Clinical trials with crystal growth conditioning as an alternative to acid-etch enamel pretreatment. Am. J. Orthod., 85(4):333-40, 1984.

Caglaroglu, M.; Sukurica, Y.; Gruel, H. G. \& Keklik, H. A comparison of shear bond strengths of six orthodontic cements. J. Orthod. Res., 2(1):17-20, 2014.

Cheng, H. Y.; Chen, C. H.; Li, C. L.; Tsai, H. H.; Chou, T. H. \& Wang, W. N. Bond strength of orthodontic light-cured resin-modified glass ionomer cement. Eur. J. Orthod., 33(2):180-4, 2001.

Choo, S. C.; Ireland, A. J. \& Sherrif, M. An in vitro investigation into the use of resin-modified glass poly(alkenoate) cements as orthodontic bonding agents. Eur J Orthod., 23(3):243-52, 2001.

Chung, C. H.; Cuozzo, P. T. \& Mante, F. K. Shear bond strength of a resin-reinforced glass ionomer cement: an in vitro comparative study. Am. J. Orthod. Dentofacial Orthop., 115(1):52-4, 1999.

Gaviria, J.; García, C. G.; Vélez, E. \& Quijano, J. The mechanism of formation of glass-ionomer cement: a theoretical study. Model. Numer. Simul. Mater. Sci., 3(4):149-54, 2013.

Godoy-Bezerra, J.; Vieira, S.; Oliveira, J. H. \& Lara, F. Shear bond strength of resin-modified glass ionomer cement with saliva present and different enamel pretreatments. Angle Orthod., 76(3):470-4, 2006.

Herion, T.; Ferracane, J. L. \& Covell, D. A. Jr. Three cements used for orthodontic banding of porcelain molars. Angle Orthod., 77(1):94-9, 2007.

Jobalia, S. B.; Valente, R. M.; de Rijk, W. G.; BeGole, E. A. \& Evans, C. A. Bond strength of visible lightcured glass ionomer orthodontic cement. Am. J. Orthod. Dentofacial Orthop., 112(2):205-8, 1997. 
MARANHÃO, K. M.; NEVES, F.; REIS, A. C.; MARANHÃO, P.; GATTI, J.; BRANDÃO, G.; KLAUTAU, E. \& AZEVEDO, D. Evaluation of the shear strength of orthodontic bands cemented with new composite using adhesive system. Int. J. Odontostomat., 12(4):407-411, 2018.

Kalcıoglu, M. T.; Uzun, I'. H.; Yalçın, M.; Malkoç, M. A.; Ögreten, A. T. \& Hanege, F. M. Evaluation on shear bond strength of different glass ionomer and hydroxy apatite cements used in ossiculoplasty. Balkan Med. J., 32(1):239, 2015

Lee, M. \& Kanavakis, G. Comparison of shear bond strength and bonding time of a novel flash-free bonding system. Angle Orthod., 86(2):265-70, 2016.

Linjawi, A. I. \& Abbassy, M. A. Comparison of shear bond strength to clinically simulated debonding of orthodontic brackets: An in vitro study. J. Orthod. Sci., 5(1):23-6, 2016.

Maranhão, K. M. \& Klautau, E. B. Novas tendências para restaurações com materiais ionoméricos. Odontol. Clin. Cient., 7(4):285-8, 2008.

Millett, D. T.; Duff, S.; Morrison, L.; Cummings, A. \& Gilmour, W. H. In vitro comparison of orthodontic band cements. Am. J. Orthod. Dentofacial Orthop., 123(1):15-20, 2003.

Millett, D. T.; Hallgren, A.; McCluskey, L. A.; McAuley, F.; Fornell, A. C.; Love, J. \& Christie, H. A clinical retrospective evaluation of 2 orthodontic band cements. Angle Orthod., 71(6):470-6, 2001

Millett, D.; Mandall, N.; Hickman, J.; Mattick, R. \& Glenny, A. M. Adhesives for fixed orthodontic bands. A systematic review. Angle Orthod., 79(1):193-9, 2009.

Movahhed, H. Z.; Ogaard, B. \& Syverud, M. An in vitro comparison of the shear bond strength of a resinreinforced glass ionomer cement and a composite adhesive for bonding orthodontic brackets. Eur. J. Orthod., 27(5):477-83, 2005.

Nakamichi, I.; Iwaku, M. \& Fusayama, T. Bovine teeth as possible substitutes in the adhesion test. J. Dent. Res., 62(10):1076-81, 1983.

Nalawade, V. A.; Pai, V. S.; Krishna, S.; Thomas, A.; Swetha, M. \& Kalladka, G. The effect of sandblasting on the retention of orthodontic bands: an in vitro study. J. Indian Orthod. Soc., 47(7):395-9, 2013.

Reynolds, I. R. A review of direct orthodontic bonding. Br. J. Orthod., 2(3):171-8, 1975.

Santos, B. M.; Pithon, M. M.; Ruellas, A. C. \& Sant'Anna, E. F. Shear bond strength of brackets bonded with hydrophilic and hydrophobic bond systems under contamination. Angle Orthod., 80(5):963-7, 2010.

Sharma, S.; Tandon, P.; Nagar, A.; Singh, G. P.; Singh, A. \& Chugh, V. K. A comparison of shear bond strength of orthodontic brackets bonded with four different orthodontic adhesives. J. Orthod. Sci., 3(2):29-33, 2014.

Williams, P. H.; Sherriff, M. \& Ireland, A. J. An investigation into the use of two polyacid-modified composite resins (compomers) and a resin-modified glass poly(alkenoate) cement used to retain orthodontic bands. Eur. J. Orthod., 27(3):245-51, 2005.

Wilson, A. D. \& Kent, B. E. A new translucent cement for dentistry. The glass ionomer cement. Br. Dent. J., 132(4):133-5, 1972.
Corresponding author:

Kalena Maranhão

Ruas dos Tamoios, 1497. Apt 1001.

Batista Campos.

Belém -PA.

BRAZIL

Email: kalenamaranhao@yahoo.com.br

Received: 21-06-2018

Accepted: 07-09-2018 